\title{
Cultural Analysis of Indian Websites
}

\author{
R.B Kulkarni \\ Deparment of Computer \\ Science \&Engineering \\ Walchand college of \\ Engineering, Solapur
}

\author{
Pooja R. Rajeshwarkar \\ Deparment of Computer \\ Science \&Engineering \\ Walchand college of \\ Engineering, Solapur
}

\author{
Dr. S.K Dixit \\ Deparment of Electronics \& \\ Telecommunication \\ Walchand college of \\ Engineering, Solapur
}

\begin{abstract}
Existence of Culture on the Web has been investigated already by many researchers to determine how different cultures represent themselves on it, and how culture affects website design and usability. Mostly these investigations are concerned to Western culture. It is also necessary to divert the attention towards non Western culture. This paper therefore presents the analysis of Indian cultural factors on Indian websites. It analyzes the presence of different Indian cultural aspects in the Indian websites. Analysis procedure depends on manual comparison and knowledge of the Indian culture. This paper proposes addition of a new dimension to the Hofstede's 5 dimension model called Integration that is mainly seen in the Indian culture
\end{abstract}

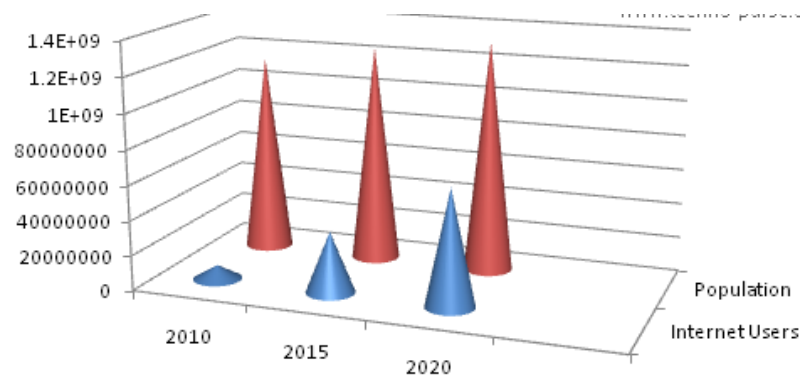

\begin{tabular}{|l|c|c|c|c}
\cline { 2 - 5 } \multicolumn{1}{c|}{} & 2010 & 2015 & 2020 & \\
\hline DInternetUsers & 81000000 & 350000000 & 665000000 & \\
\hline$\square$ Population & $1,150,000,000$ & 12560000000 & 1326093000 & \\
\hline
\end{tabular}

Fig 1. Internet users in India

\section{General Terms}

Cultural Analysis of Websites

\section{Keywords}

Indian culture, culture, Indian websites, Hofsted's cultural factors

\section{INTRODUCTION}

The whole world is going crazy about Internet usage and India too, is on the same way. Compare to last year (2010) $28 \%$ rise in Internet users is seen in 2011. Statistics show that in 201050.95 million people used Internet and in 2011 this number increased to 65.06 million i.e. $28 \%$ rise [9]. Not only this, but the study has revealed that in coming 10 years, this growth trend will continue in India. This trend is as shown in the graph given below.[10]
These statistics indicate that many people with different cultures, area, and region are observing the websites. To make the website more interesting and to attract more users (may be of different cultures) to the website it is necessary to design the website that will attract the people.

Thus, design becomes the main factor of success of a website. While designing a website the designer should think as the user of that website. In this situation he should not ignore the most important aspect of the user's life that is his "culture".

Definitions of culture vary depending on the view of the user. User may prefer anthropological or sociological view of the culture. Each viewpoint has its own perspective. According to Chen, Mashhadi, Ang and Harkrider (1999)[1], anthropologists refer to the behavioral customs, the manners and the interests of society, while sociologists view culture as socially determined ways of thinking and acting that people acquire as a member of society.

Culture can be defined as the way of life of a group of people. A people's culture is demonstrated through its values, beliefs and education. Culture thus shapes and is shaped by language, ethnicity, religion, class, power, history, geography, gender, lifestyle, values, beliefs, traditions and ways of thinking and doing (Scheel and Branch, as cited in Henderson, 1996). Henderson (1996) [2] also suggested that culture is the showcase of the patterns of thinking and behavior that result through a group's adaptation to its changing environment.

The objective here is that, by customizing web page design through the incorporation of culturally appropriate design features, it becomes both more attractive and more functional for its users (Nielsen 2000).

Davis, Wang, \& Lindridge, 2007, Dormann, 2006 stated that The cultural factors in a design process of a web page increase the functional and aesthetic perceivability, quality, and success of the design simultaneously because they are affected from their own cultural identities in the knowledge acquisition and sensory perception processes. Inspired from this statement, this paper will dig more to see how Indian culture affects design of Indian websites.

India is culturally rich and must be having much impact of its culture on the websites. India is religious and family preferred country. It definitely becomes a research point to investigate the presence of Indian culture in Indian sites. In accordance to this we will refer to some foreign websites to effectively understand the cultural factors affecting the Indian websites. 
In the next section the literature survey presents briefly the concerned work of researchers regarding cultural impact on web design. Further we will see the Indian cultural factors and verify how they affect the Indian websites. In the conclusion we present result of this research. Conclusion also tries to add a new dimension to the Indian culture i.e "Integration".

\section{LITERATURE REVIEW}

Table 1. Summary of Hofstede's dimensions

\begin{tabular}{|l|l|}
\hline Dimension & Explanation \\
\hline $\begin{array}{l}\text { Power/distanc } \\
\text { e (PD) }\end{array}$ & $\begin{array}{l}\text { Measure of power that the subordinates } \\
\text { have, as compared to their superiors } \\
\text { especially within institutions and } \\
\text { organizations. }\end{array}$ \\
\hline $\begin{array}{l}\text { Collectivism } \\
\text { vs }\end{array}$ & $\begin{array}{l}\text { Collectivism refers to the culture where } \\
\text { family bonds or group bonds are strong. } \\
\text { People throughout lifetime continue to } \\
\text { protect them in exchange for unquestioning } \\
\text { loyalty. Individualism pertains to societies } \\
\text { in which the ties between individuals are } \\
\text { loose: everyone is expected to look after } \\
\text { himself or herself and his or her immediate } \\
\text { family. }\end{array}$ \\
\hline $\begin{array}{l}\text { Femininity vs } \\
\text { Masculinity }\end{array}$ & $\begin{array}{l}\text { Masculinity pertains to the culture in which } \\
\text { the gender roles are clearly distinct; } \\
\text { femininity represents the culture in which } \\
\text { the gender roles are not distinct or they } \\
\text { overlap. }\end{array}$ \\
\hline $\begin{array}{l}\text { Uncertainty/A } \\
\text { voidance } \\
\text { Index(UAI) }\end{array}$ & $\begin{array}{l}\text { Measure of tendency of people of the } \\
\text { culture getting threatened by uncertain or } \\
\text { unknown situations }\end{array}$ \\
\hline Orientation & $\begin{array}{l}\text { Long-term orientation means sustaining of } \\
\text { virtues oriented towards future rewards, in } \\
\text { particular perseverance and thrift. Short- } \\
\text { term orientation symbolizes the fostering } \\
\text { of virtues related to the past and the present } \\
\text { in particular respect for tradition and } \\
\text { fulfilling social obligations }\end{array}$ \\
\hline
\end{tabular}

According to Hofstede (1991) culture is a collection of common thoughts that discriminate an individual who belongs to a certain group or class. Thus, Hofstede has an anthropological view of culture. This paper will follow hofstede's definition of culture. Hofstede has a great contribution in this field. Hofstede.s cultural model consists of five dimensions. Each dimension groups together phenomena in a society that were empirically found to occur in combination. [3] Hofstede.s work on cultures in organizations formed a framework of four dimensions culture identified across nations. The fifth dimension of Long- vs. Short- term Orientation was added after Michael Harris Bond discovered it. The 5 dimensions can be explained briefly as shown in table 1. Table 2 shows the statistics of Hofstede's dimensions on Indian culture and comparison made with that of the rest of the world. The inference column helps to know how the
Indian culture is with respect to other cultures. Figures 2 and 3 show the graphical representation of this statistics. [3]

Table 2. Comparing India and world with respect to Hofstede's dimensiuons

\begin{tabular}{|c|c|c|c|}
\hline Dimensions & India & World & Inference \\
\hline PDI & 77 & 56.5 & $\begin{array}{l}\text { Indicates a high level of } \\
\text { inequality of power and } \\
\text { wealth within the } \\
\text { society }\end{array}$ \\
\hline IDV & 45 & 40 & $\begin{array}{l}\text { Collectivism is seen in } \\
\text { Indian culture. People } \\
\text { from birth onwards are } \\
\text { integrated into strong, } \\
\text { cohesive in-groups, } \\
\text { often extended families } \\
\text { (with uncles, aunts and } \\
\text { grandparents) which } \\
\text { continue protecting } \\
\text { them in exchange for } \\
\text { unquestioning loyalty. }\end{array}$ \\
\hline MAS & 56 & 51 & $\begin{array}{l}\text { The gap between values } \\
\text { of men and women is } \\
\text { greater. It may also } \\
\text { generate a more } \\
\text { competitive and } \\
\text { assertive female } \\
\text { population, although } \\
\text { still less than the male } \\
\text { population. }\end{array}$ \\
\hline UAI & 40 & 65 & $\begin{array}{l}\text { Culture may be more } \\
\text { open to unstructured } \\
\text { ideas and situations. } \\
\text { fewer rules and } \\
\text { regulations with which } \\
\text { to attempt control of } \\
\text { every unknown and } \\
\text { unexpected event or } \\
\text { situation }\end{array}$ \\
\hline LTO & 61 & 48 & $\begin{array}{l}\text { Indicates a culture that } \\
\text { is perseverant and } \\
\text { parsimonious. }\end{array}$ \\
\hline
\end{tabular}

Nantel and Glaser (2008) proved that the usability of a website increased when the website was originally presented in the native language of the user. Even if translation of a site is possible, it did not touch the users' heart like the originally developed native language site.

Nitish Singh has explained a framework for cultural analysis of the website content. He explains that there are 3 levels viz: perceptual, behavioral, and symbolic dimensions of cultural reality to study the web content. It is believed that such a frame work helps in holistic analysis of the web content. At the perceptual level the emphasis is on language used and color categories and a combination of etic (belief or behavior 
by observation or by logical aspect in that observation) and emic (behavior meaningful to the actor either consciously or inconciously ) approaches is recommended. At the behavioral level the stress is on cultural values and an etic mode of enquiry is preferred.

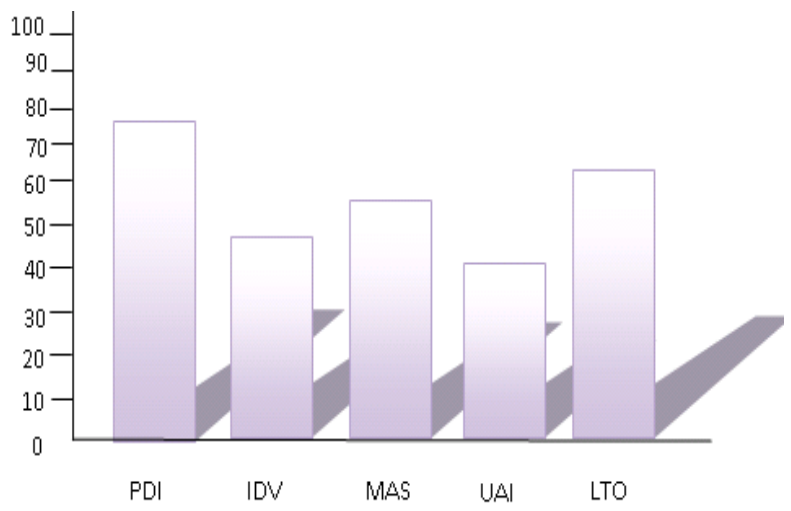

Fig2: Indian Scenario

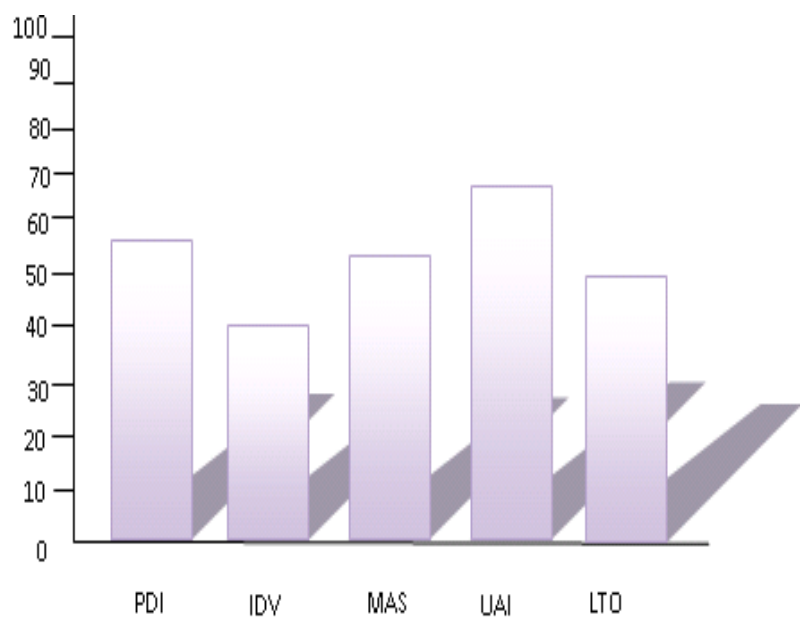

Fig3: World Scenario

Finally at the symbolic level the emphasis is on emic understanding of signs and emphasis is on emic understanding of signs and symbols of the society.

In this paper we will consider the so called Perceptual factors and the analysis will show that these 3 levels are interconnected to each other. On analyzing perceptual factors like Language, colors, pictures used in the website we can draw inferences that are actually at the behavioral and symbolic levels. From perceptual factors we can conclude the cultural values of that culture and from that further we can infer how the cultural values are expressed and understood. Therefore in the next section we introduce 3 perceptual factors and one factor at symbolic level. The Analysis result will be at behavioral and symbolic level.

\section{CULTURAL FACTORS}

Some factors are incorporated in the nature and behavior of the people as the virtue of their culture. Indian culture is an ancient culture and has diversity as its significance. Indian website therefore must have a reflection of all these diversities so that it can reach to every user's heart. Unlike in other cultures such diversity is not found. So designing Indian websites is more difficult than designing website for other culture because it has to incorporate many variations at a time in itself.

Some of the factors of Indian culture are explained below-

1. Language: Language spoken in a culture exists in context with that culture. Language influence deeply on people's thinking, storing \& encoding information, usability of website, color preferences [5] [6]. Indian culture has many sub-cultures and their own languages, so it is necessary to decide which language to use in the website. A deciding factor may be the point that your website will be functional in which particular region of the country. Adopting language of that region will help you draw more users to your sites. Analyze the style of the language and the target audience. Options may be given for translation in secondary language, if necessary. But translation is not that effective, as it may have many communication errors. Hindi is the national language of India so creating website in Hindi will make the site valid irrespective of the sub-cultures.

2. Pictures: Images can convey subtle cultural messages to their users. These can speak volumes about your website at the first look, without even reading the content of your site. They create first impression of your site. So, pictures if not selected properly may result in negative connotations that may lose the stickiness property of the website. Proper selection of images means, while including pictures it is wise to tailor these to what the target audience will look positively upon. It is through pictures that websites can either relate to an audience or repel them.

3. Symbols: Symbols express feeling in a short-cut format. While using symbols it is necessary to be extra careful because same symbol may mean different or may be void in different culture. For instance the holy symbol "AUM" in Indian culture has no meaning in other cultures. "Swastika" is religious in India while in western culture it might be interpreted as something related to the Nazis due to its resemblance.

4. Colors: Color is a powerful and important factor, which is linked to religious, cultural, political and social influences. Color can affect our mood and nature. Different colors symbolize different things in different places. This is extremely important for designers to know because without such knowledge you risk offending your entire target audience.

\section{CULTURAL ANALYSIS}

\subsection{Analysis of India's Portal}

The above cultural factors are considered to analyze the Indian websites. As an example of Indian website, let us take the India's National Portal as shown in fig.4.

1. Language: even though the language is English when one opens the site, there is an option of translation in Hindi. So this site reflects the culture of India as Hindi is the national language. We may also add the options of translating in other Indian languages too. Translation is available in Spanish 
(Espanol) language. So if we take language as a metric we can conclude that Indian sites reflect the Indian culture by making available the translation option. As English in universal language all websites are originally built in English language. This trend is actually observed in the sites over the world.

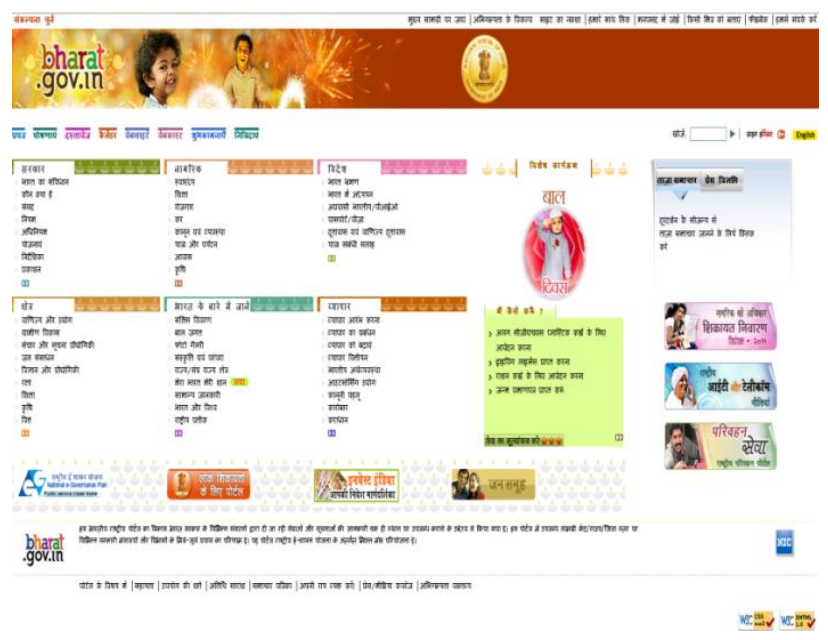

Fig: 4 India's Portal Site (November 5 2011)

2. Pictures: in India's portal we can see picture of children but in US portal we will not find any such picture. In fact US portal seems to be a professional site. Here it reflects the "Individualism" (as stated by Hofstede) of the western (U.S) culture. Such picture in India's portal reflects that the people are emotionally attached to each other, in Hofsted's words we can say that their "Collectivism" is reflected.

3. Symbols: India's portal carries many symbols that are relevant in Indian culture itself. For example: the color strip after each navigation option shows lines of lighted lamps that carry cultural significance. This webpage snapshot was taken during the festival of lights in India i.e Diwali so the portal exhibits these lamps. Similarly the picture of children symbolize that children's day is about to be celebrated (Birthday of Jawaharlal Nehru who was fond of children) on $14^{\text {th }}$ November. Especially the child wearing red rose symbolizes that Jawaharlal Nehru was fond of red roses too. All these symbols indicate cultural factors of India. The banner of India's portal has the national emblem of India i.e. the four-headed Lion. The bald eagle in US portal is seen as it is the national bird of USA. The stars in the same picture can be related to the presence of stars in the US national flag that symbolize states of USA. Thus if we change the context of symbols of each of these portals they are meaningless to them. Mostly if we consider stars in Indian culture would again mean some symbol related to Diwali festival.

4. Colors: the India's portal is exhibiting more than two colors, even though the background is white. The way "bharat" is written itself suggests the presence of diversity in Indian culture. The strips at the navigation option each have different color making the portal colorful. Use of multiple colors suggest that the culture respects arts and the culture is full of people with different taste and choice. It suggests that the culture wants to adhere every individual to each other by accepting him along with his choice. If we consider the US portal we can see that it has only 2 colors on white background i.e blue and red. We can link these colors to those on the national flag. This suggests that the people of follow single culture and that there is not much diversity. Even this portal does not have the options of changing themes that is available in the India's portal. Each theme is again colorful as the one shown in the fig4.

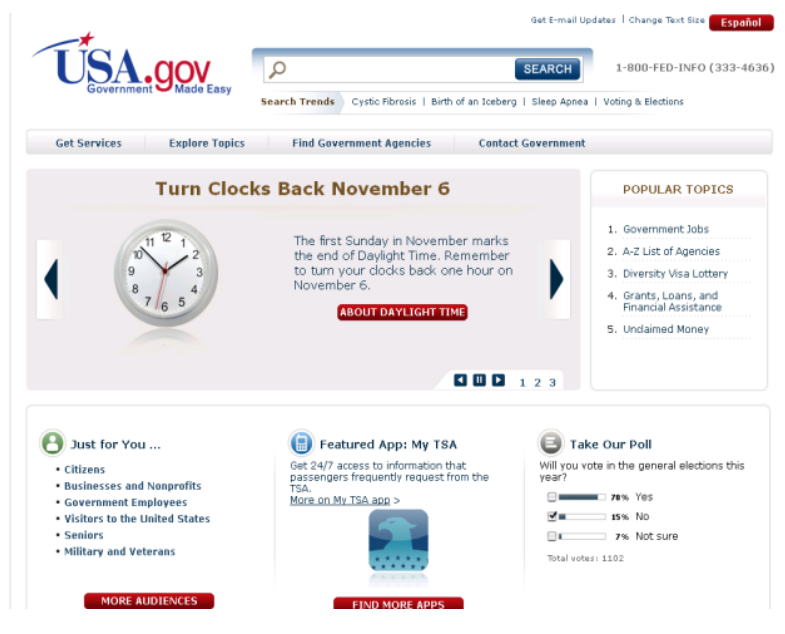

Fig: 5 US Portal Site (November 5 2011)

\subsection{Analysis of other Indian websites}

In this subsection many famous Indian sites are considered and the above four factors are considered to analyze them with respect to culture. The results are displayed in tabular format (table 4.). Points are given out of 10 to each factor. If the sum is above $20(50 \%)$ then it is said that the site fairly passed in the cultural analysis. To make analysis more effective and to exhibit the cultural difference, we have compared them qualitatively with their corresponding US sites' design (representing western culture) and Chinese or Japanese sites' design (representing Eastern culture). After such a proper analysis we then assign them the appropriate scores. We will interpret the scores of each site separately as below

\section{Mc Donald's:}

a. Language: The site does not have an Indian language \& no translation option is provided. Mc Donald's china is in Chinese language. So this site scores 0 .

b. Pictures: there are some pictures related to Indian culture. So it scores 8 points

c. Symbols: the parrot holding a card in its beak symbolizes the forecast prediction which is typically famous in Indian culture. So it scores 8 .

d. Colors: colors used are bright and it follows its theme color which is red but offers themes in different bright colors so it scores 8 .

2. IBM's site:

a. Language: The site too, does not have an Indian language \& no translation option is provided. IBM Japan is in Japanese language. So this site scores 0.

b. Pictures: no pictures are related to Indian culture so it scores a 0 
c. Symbols: symbols used do not reflect any cultural aspect of India

d. Colors: there is no much difference in use of colors, between the US site and Indian site except some bright colors near the banner of the IBM India site so it scores 5.

3. Yahoo:

a. Language: the entire site is available in Hindi at the site (http://in.jagran.yahoo.com/). But it should open on entering yahoo.com which does not happen so it scores 8 not 10

b. Pictures: all pictures are related to Indian culture so it scores 10

c. Symbols: symbols used reflect cultural aspect of India. Eg: the astrology related symbol on the page

d. Colors: there is no much difference in use of colors, between the US site and Indian site except some bright colors near the banner of the IBM India site so it scores 5 .

4. Solapur university site:

a. Language: The site is in English but it has a translation option in Marathi language as this university belongs to a city in Maharashtra. But many parts of the page remain in English after translation so it can score only 6.

b. Pictures: all pictures reflect Indian culture so it scores 10

c. Symbols: Especially the Solapur university symbol reflects the cultural aspect of India

d. Colors: different themes are available for different moods of people while the colors are bright which typically reflects Indian culture.

\section{Coca cola site:}

a. Language: this site is entirely in English without any translation options so it has scored 0

b. Pictures: it incorporates pictures related to Indian culture so it has 10 points

c. Symbols: there are no symbols that may be related to Indian culture

d. Colors: many bright colors including red, which is theme color of coca cola are used which reflect

\subsection{Analysis Results}

As we have evaluated these sites other sites are also evaluated in the same fashion and recorded in Table 3. On studying the table we will come to know which of these sites has really incorporated the Indian culture in itself. Even if the sites are of Indian origin we find that the language used is English for almost all the sites. Indian sites speak with pictures. Majority of these sites are using such pictures that really reflect the influence of Indian culture on them.

1. Language: on analyzing many Indian websites it is found that these websites are in English and only few of them have translation facility. Even after translation there are many things that remain in English like the advertisements, etc. but it is found that the sites belonging to the Eastern culture (Japanese and Chinese websites are in Japanese or Chinese languages) strictly have the local language on their website with an option of translation in English. Thus they give second preference to English unlike Indian websites. Moreover, it is observed that there is a significant change in webpage design and layout after this translation in Indian websites while such a change is negligible in Eastern cultural websites. So we find that there might be some relation between language and webpage design and layout.

2. Pictures: majority of Indian websites have Indian pictures in them. Only a few of them that do not have such pictures are MNC sites which need to be localized more. It is found that Indian culture is expressed more using pictures rather than Language.

3. Symbols: Indian websites make very less use of symbols. Symbols are found mainly in Government websites only.culture can be expressed using Symbols but it is found that this factor is less exploited in Indian websites.

4. Colors: most of the Indian websites have multiple colors used. There is no fixed combination of two colors like those found in Western and Eastern websites. Mostly both of them choose white as one of the color. In Indian websites we find use of many bright colors. We also find a peculiar feature in Indian website which is regarding Change of theme. Such a feature is not found either in Western or Eastern websites. This reflects that the Indian culture is having people with different mood and it expresses emotions more than that of the other cultures.

Thus from the perceptual factors we go to the Behavioral level that reflects the cultural values like family bonding, truth, serenity, justice, sharing, religious impact, etc. In fact it is evident that the 5 dimensions stated by Hofstede are at the behavioral level that actually classifies cultures on their values like individualism, power distance index, etc. The fourth factor of analysis i.e Symbol, exhibits the cultural point of view for the signs and symbols used in the website, which forms the symbolic level.

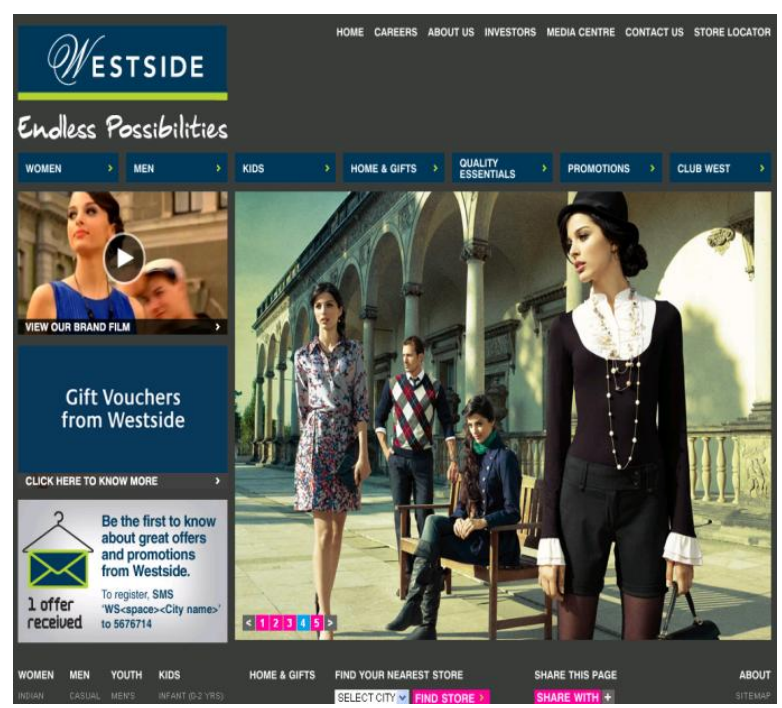

Fig:6 Indian site influenced by western culture 
An interesting Analysis Result is that Indian Culture has one more cultural value at behavioral level which can be termed as "Integrity". Integrity refers to merging of other culture easily into itself. Thus Indian culture reflects the impact of globalization that has affected it in the websites. Indian culture is hugely affected by Western culture. This can be said by the fact that majority sites of India use and prefer English Language. Many of them have their design influenced by Western Culture. A live example is the site of Westside (http://www.mywestside.com/Home.aspx) fig. 6.

\section{CONCLUSION}

Indian Culture is not fully reflected in the Indian websites. There may be many factors responsible for this viz: modernization, globalization if the Indian society. Unlike other cultures especially Eastern culture Indian websites lack in expressing the Indian culture. By analyzing the Indian websites we can safely conclude that there is presence of "Modern" Indian culture on the web. The websites reflect the culture that is currently being practiced by the Indian society. This law could be applied in general for any website of any culture. Websites will change or modernize with the culture as and when it changes. Thus website is a mirror of the society's culture. Localization or globalization of a website to adapt to a culture is to be made keeping in mind the audience of that website and their culture.

\section{ACKNOWLEDGMENTS}

Authors are thankful to the Institution with which they are associated to allow them to participate in journal publishing programs, which provide a platform for their research work to showcase to the world.

\section{REFERENCES}

[1] Chen, A., Mashhadi, A., Ang, D., \& Harkrider, N. (1999). Cultural issues in the design of technology- enhanced learning systems. British Journal of Educational Technology, 30 (3), 217-230.

[2] Henderson, L. (1996). Instructional design of interactive multimedia: A cultural critique. Educational Technology Research and Development, 44 (4), 85-104. (ERIC Document Reproduction Service EJ362295).

[3] Insights on Hofstede's research into national and organizational culture: http://www.geerthofstede.com/index.shtml (reference for the figures $2 \&$ 3 and tables $1 \& 2$ )

[4] The Impact of Target Culture on Design by Anitha Kasturi Rangan Rochester Institute of Technology

[5] Analyzing Cultural Sensitivity of Websites A Normative Framework by Nitish Singh

[6] Multilingual Website Usability: Cultural context by Mathew Hiller

[7] The Impact of Culture on Web Design and Ecommerce Effectiveness in Chinese Online Consumers: An Online Survey of Five New Zealand Websites by Florian Stroehle

[8] Cultural Variability in Web Content: A Comparative Analysis of American and Turkish Websites by Gaye Karaçay Aydın, Elif Akben-Selçuk and Aslı Elif AydınAltınoklar

[9] 65 Million Active Internet Users in India: http://trak.in/tags/business/2011/08/23/india-onlineinternet-users-survey-report-2011/ (figure 1)

[10] What IRCTC can Learn from redBus Cloud Implementation? Available at : http://www.technopulse.com/2011/01/what-irctc-learn-redbus-cloudiaas.html 
In this paper, it is considered that the sites that are made for India are Indian websites then they may be of Indian originated company's site or an MNC's site.

Table 3. Cultural Analysis of Indian websites

\begin{tabular}{|c|c|c|c|c|c|}
\hline Site & Language & Pictures & Symbols & Colors & Total \\
\hline 1. www.medonaldsindia.com/ & 0 & 6 & 8 & 8 & 22 \\
\hline 2. http://www.ibm.com/in/en/ & 0 & 0 & 0 & 5 & 5 \\
\hline 3. http://in.yahoo.com/(http://in.jagran.yahoo.com/) & 8 & 10 & 10 & 7 & 35 \\
\hline 4. http://su.digitaluniversity.ac/default.aspx & 6 & 10 & 10 & 8 & 34 \\
\hline 5. http://www.coca-colaindia.com/ & 0 & 10 & 0 & 8 & 18 \\
\hline 6. http://www.siemens.com/entry/in/en/ & 0 & 0 & 0 & 0 & 0 \\
\hline 7. http://www.travelocity.co.in/ & 0 & 0 & 5 & 0 & 5 \\
\hline 8. http://www.cafecoffeeday.com/ & 0 & 5 & 0 & 8 & 13 \\
\hline $\begin{array}{l}\text { 9. http://home.airindia.in/SBCMS/WebPages/Home.aspx } \\
\text { (https://book.airindia.in/itd/itd/Home) }\end{array}$ & 7 & 8 & 8 & 7 & 30 \\
\hline 10. http://www.indianrail.gov.in/hindex.html & 9 & 10 & 8 & 8 & 35 \\
\hline 11. http://www.levi.co.in/ & 0 & 0 & 0 & 0 & 0 \\
\hline 12. http://www.disney.in/DisneyChannel/ & 0 & 5 & 0 & 6 & 11 \\
\hline 13. http://www.mywestside.com/Home.aspx & 0 & 5 & 0 & 5 & 10 \\
\hline 14. http://aajtak.intoday.in/ & 9 & 10 & 5 & 10 & 34 \\
\hline 15. http://www.lilavatihospital.com/index.asp & 0 & 8 & 5 & 7 & 20 \\
\hline
\end{tabular}

